\title{
Análise de Riscos na Gestão Coordenada de Fronteiras: A ConvergênCia entre os Direitos Humanos e a Segurança Nacional NA MigraÇão INTERNACIONAL
}

\author{
RISK ANALYSIS IN COORDINATED BORDER \\ Management: The ConVERGENCE BetWEeN \\ Human Rights aND National SECURITY IN \\ INTERNATIONAL MIGRATION
}

\begin{abstract}
Análisis de Riesgos en la Gestión CoORdinada DE FRONTERAS: LA CONVERGENCLA ENTRE DERECHOS HuMANOS Y SEGURIDAD NACIONAL ENLAMIGRACIÓN INTERNACIONAL
\end{abstract}

Felipe Scarpelli de Andrade

Polícia Federal, Brasília/DF, Brasil scarpellifelipe@gmail.com

(6) http://lattes.cnpq.br/6780113389939890

Priscila Aparecida de Macêdo e Silva

Polícia Federal, Brasília/DF, Brasil correiopriscila@gmail.com

\section{RESUMO}

O artigo tem por objetivo estabelecer diretrizes gerais de uma metodologia de análise de riscos ao apresentar orientações sobre como garantir que as atividades de gestão e governança das fronteiras cumpram os padrões de direitos humanos, ao mesmo tempo em que permitam assegurar a segurança nacional. Dessa forma, a iniciativa vem no sentido de expor a relevância de um processo estruturado para medir os riscos relacionados à proteção dos direitos fundamentais dos migrantes e no interesse legítimo dos países em salvaguardar as suas fronteiras. Trata-se da convergência entre os direitos humanos e a segurança nacional na busca pela eficiência de uma Gestão Coordenada de Fronteiras. 
Palavras-Chave: análise de riscos; gestão de riscos; gestão coordenada de fronteiras; direitos humanos.

\section{ABSTRACT}

The article aims to establish general guidelines for a risk analysis methodology by providing guidance on how to ensure that border management and governance activities comply with human rights standards while ensuring national security. In this way, the initiative aims at exposing the relevance of a structured process to measure the risks related to the protection of the fundamental rights of migrants and in the legitimate interest of countries in safeguarding their borders. It is about the convergence between human rights and national security, in the search for the efficiency of a Coordinated Border Management.

KEYwORDS: Risk Analysis. Risk management. Coordinated Border Management. Human Rights.

\section{RESUMEN}

El artículo tiene como objetivo establecer pautas generales para una metodología de análisis de riesgos al proporcionar orientación sobre cómo garantizar que las actividades de gestión y gobernanza fronterizas cumplan con los estándares de derechos humanos, al tiempo que se garantiza la seguridad nacional. Así, la iniciativa tiene como objetivo exponer la relevancia de un proceso estructurado para medir los riesgos relacionados con la protección de los derechos fundamentales de los migrantes y el interés legítimo de los países en salvaguardar sus fronteras. Se trata de la convergencia entre derechos humanos y seguridad nacional en la búsqueda de la eficiencia de una Gestión Fronteriza Coordinada.

Palabras clave: Análisis de riesgos. Gestión de riesgos. Gestión coordinada de fronteras. Derechos humanos.

\section{INTRODUÇÃo}

A migração internacional está intimamente ligada à história da humanidade. É considerada como um fenômeno diversificado e complexo, já que possui distintas causas, como econômica, religiosa, cultural, política, desastres naturais ou simplesmente pela expansão populacional. $O$ presente trabalho aborda a temática sob o foco da convergência entre os direitos humanos e a segurança nacional, ao identificar ferramentas para uma gestão adequada de fronteiras, de maneira integrada, segura, coordenada e digna em um contexto transver- 
sal, contribuindo, portanto, com a reflexão acerca da necessidade do uso de ferramentas como a de Análise de Riscos para assegurar uma adequada gestão coordenada de fronteiras, com respeito aos direitos humanos e à segurança do país.

Os deslocamentos de pessoas são frequentemente necessários e desejados pelos países no contexto da globalização (MARTINE, 2005), em que pese a existência equivocada de argumentos como invasão migratória, riscos de desemprego, a perda da identidade nacional, aumento de crime ou até mesmo do terrorismo. A intensificação dos fluxos migratórios internacionais das últimas décadas provocou o aumento do número de países orientados a regulamentar e até a reduzir a imigração (CORREIA, 2009).

Acerca dos deslocamentos, o South American Migration Report n. 3 (OIM, 2020) indica que a América do Sul tem sido uma região de origem, trânsito e destino de migrantes internacionais, em torno de 10 milhões de pessoas de diferentes países. No referido relatório sobre tendências de migração na América, houve o cotejo entre os anos de 2010 e 2019 e restou consignado que a migração intrarregional cresceu em grau superior, quando comparado ao deslocamento para países mais desenvolvidos (extrarregional), numa dinâmica recente. Aproximadamente $80 \%$ dos imigrantes na América do Sul são intrarregionais, sobretudo pelo crescimento da migração venezuelana.

Especificamente no Brasil, cabe destacar que a formação populacional foi construída por várias nacionalidades ao longo de sua história (IBGE, 2007), que vai desde os povos originários e africanos escravizados, até migrações de portugueses, italianos, japoneses, alemães, espanhóis, árabes e, mais recentemente, bolivianos, senegaleses, angolanos, congoleses, sírios, haitianos e venezuelanos. O ingresso de migrantes motivados a reconstruir suas vidas também teve crescimento na última década, sobretudo em virtude de crises econômicas, instabilidades sociais e políticas, desastres naturais e conflitos armados (BAENINGER et. al., 2018). Outra característica impulsionadora desse fluxo deve-se ao fato do crescimento econômico e de novas oportunidades que surgiram no País nas últimas décadas.

Pelo gráfico a seguir, é possível comparar o movimento migratório de entradas e saídas do Brasil no período de 2018 a 2020, e ob- 
servar que o mês de março de 2020 apresentou queda abrupta no fluxo migratório, acima de $40 \%$, determinada pelas restrições de mobilidade ante a declaração de pandemia do novo coronavírus (SARS-CoV-2) pela Organização Mundial da Saúde (OMS):

Imagem 1 - Controle de fluxo migratório no Brasil no período de 2018-2020

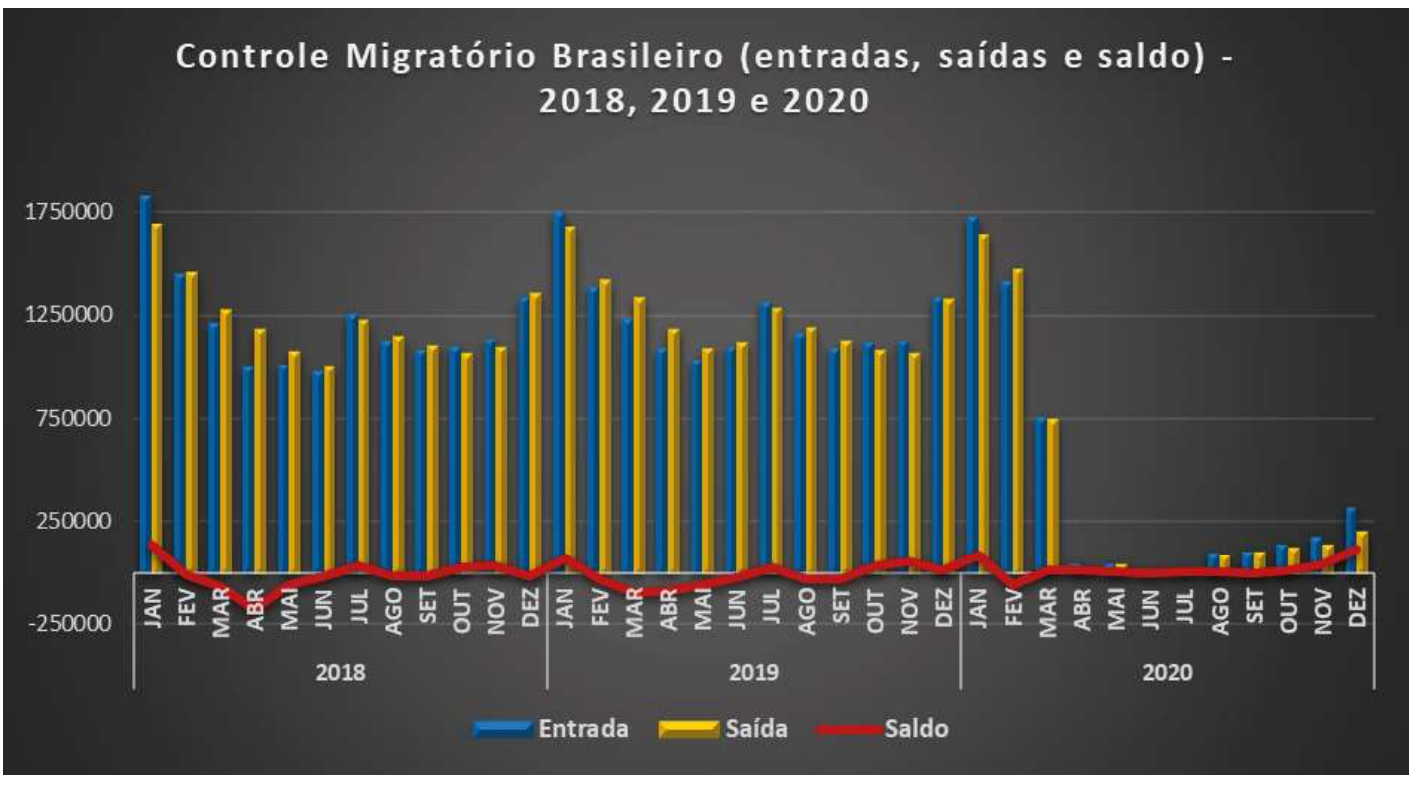

Fonte: Elaborado pelos autores, a partir de dados do Sistema de Tráfego Internacional da Polícia Federal, disponível no site do OBMIGRA

A preocupação de haver uma coordenação internacional para lidar com problemas sanitários e evitar a propagação de enfermidades entre fronteiras internacionais existe desde o século XIX. Em razão da Pandemia, os governos reforçaram as medidas restritivas, tais como o fechamento de suas fronteiras, com o objetivo de mitigar o impacto da enfermidade nos territórios (DUVAL et. al., 2020). Contudo, em muitos países, tem ocorrido uma cautelosa reabertura das fronteiras, com observância a protocolos sanitários, além de adotarem critérios na reintrodução de controles internos, tais como epidemiológicos, de reciprocidade, interesses nacionais e econômicos. Neste caso, especialmente com ações direcionadas a facilitar o turismo, que representa um papel significativo na reconstrução econômica, com procedimentos voltados à submissão ao teste de detecção do vírus SARS-CoV-2, controle de temperatura corporal, até a tentativa de zonas fechadas de viagem.

O processo de reabertura não se tem revelado uniforme, da mesma forma que as peculiaridades locais também diferenciam os países (OIM, 2021). Alguns apresentam uma postura mais conservadora, 
enquanto outros desejam retirar de forma célere as restrições acerca da mobilidade humana. No caso da União Europeia, a recomendação é de serem revisadas de forma periódica as ações para consentir ou restringir a transposição de suas fronteiras, conforme a situação epidemiológica apresentada no país ante as medidas anteriormente adotadas.

Apesar das dificuldades ora apresentadas pela emergência em saúde pública, é imperioso antecipar o cenário com o retorno da dinâmica migratória, visto que o fechamento das fronteiras foi determinado como medida necessária para conter a disseminação do novo coronavírus, mas a reabertura é inevitável. Ainda durante a restrição, foi possível notar a pressão para deslocamentos, especialmente entre cidades-gêmeas, que são estratégicas no contexto cultural e econômico brasileiro, sobretudo pela abertura do mercado Sul-Americano.

Nesse contexto e diante das crescentes dimensões dos deslocamentos internacionais, torna-se necessário discutir e desenvolver o assunto para conciliar as preocupações relativas à segurança nacional à recepção de migrantes de maneira segura, coordenada e digna, notadamente daqueles mais vulneráveis (TORELLY et. al., 2017), que são mais suscetíveis às práticas ilícitas de redes criminosas, sobretudo no cenário pós-pandemia, resguardando-se os direitos humanos. Neste caso, é importante evidenciar a experiência do Brasil com a Operação Acolhida, ao determinar procedimentos, inclusive relacionados à saúde, para receber com segurança e dignidade os imigrantes venezuelanos (BRASIL et. al., 2021).

Dessa forma, é preciso reorientar as políticas nacionais de desenvolvimento e a cooperação internacional, a fim de se estabelecer os delineamentos necessários para uma gestão adequada de fronteiras, ao promover uma melhor governança destes fluxos, tratar e sistematizar dados e informações de campo com uso de ferramentas de inteligência, apoiar os migrantes e promover o acesso a seus direitos na busca pela conformidade entre a segurança nacional e os direitos humanos.

Destarte, convém desenvolver um processo sistemático de gestão do conhecimento de forma integrada, considerar os múltiplos atores envolvidos no processo, estabelecer objetivos fundamentais, determinar métricas para medir os riscos relacionados ao tema e alinhar 
as ações de quem executa as políticas migratórias com os responsáveis pela sua formulação: trata-se da Gestão Coordenada de Fronteiras.

\section{Gestão Coordenada de Fronteiras}

O termo gestão de fronteiras possui distintos conceitos que variam de acordo com o enfoque, como a Gestão Humanitária de Fronteiras, Gestão Coordenada de Fronteiras, Gestão Coordenada para Migração da Fronteira ou simplesmente Gestão de Fronteiras.

Por exemplo, o Escritório do Alto Comissariado das Nações Unidas para os Direitos Humanos, sobre Direitos Humanos nas Fronteiras Internacionais ${ }^{1}$ (2014), fornece orientações acerca de como garantir que as atividades de gestão e governança das fronteiras cumpram os padrões de direitos humanos. Já no Glossário sobre Migrações, da Organização Internacional para as Migrações (OIM, 2019), a gestão de fronteiras envolve a facilitação de fluxos autorizados de pessoas e bens, e a detecção e prevenção da entrada irregular de estrangeiros e mercadorias em um dado país. De uma forma geral, as definições referem-se ao equilíbrio entre as medidas de facilitação da entrada de viajantes habituais e a detecção de pessoas que precisam de assistência imediata ou tenham proteção internacional, e às questões aduaneiras e situações de pessoas com intenções criminosas.

É importante salientar que os Estados, no exercício de sua soberania, possuem a prerrogativa para estabelecerem quais os processos de controle deverão utilizar, ou seja, qual enfoque será dado ao controle de sua fronteira. Detêm, igualmente, a responsabilidade de garantir que a legislação, as políticas e as práticas de gestão de fronteiras cumpram e respeitem os direitos de todas as pessoas que atravessam os seus limites fronteiriços.

Segundo o Banco Interamericano de Desenvolvimento (2019), há basicamente dois enfoques de controle de fronteira: abordagem de controle restritivo e abordagem de controle facilitado. No restritivo os procedimentos são orientados pelos conceitos de soberania, segurança

1 https://www.ohchr.org/Documents/Issues/Migration/OHCHR_Recommended_Principles_ Guidelines.pdf 
nacional e pela garantia de interesses nacionais, ao passo que no controle facilitado, a componente Direitos Humanos se destaca como o eixo dos procedimentos, sendo a segurança enquadrada nos processos de prevenção e proteção. Sem embargo, é possível encontrar modelos híbridos, que contemplem características das mencionadas abordagens.

Imagem 2 - Enfoques de controle de fronteira

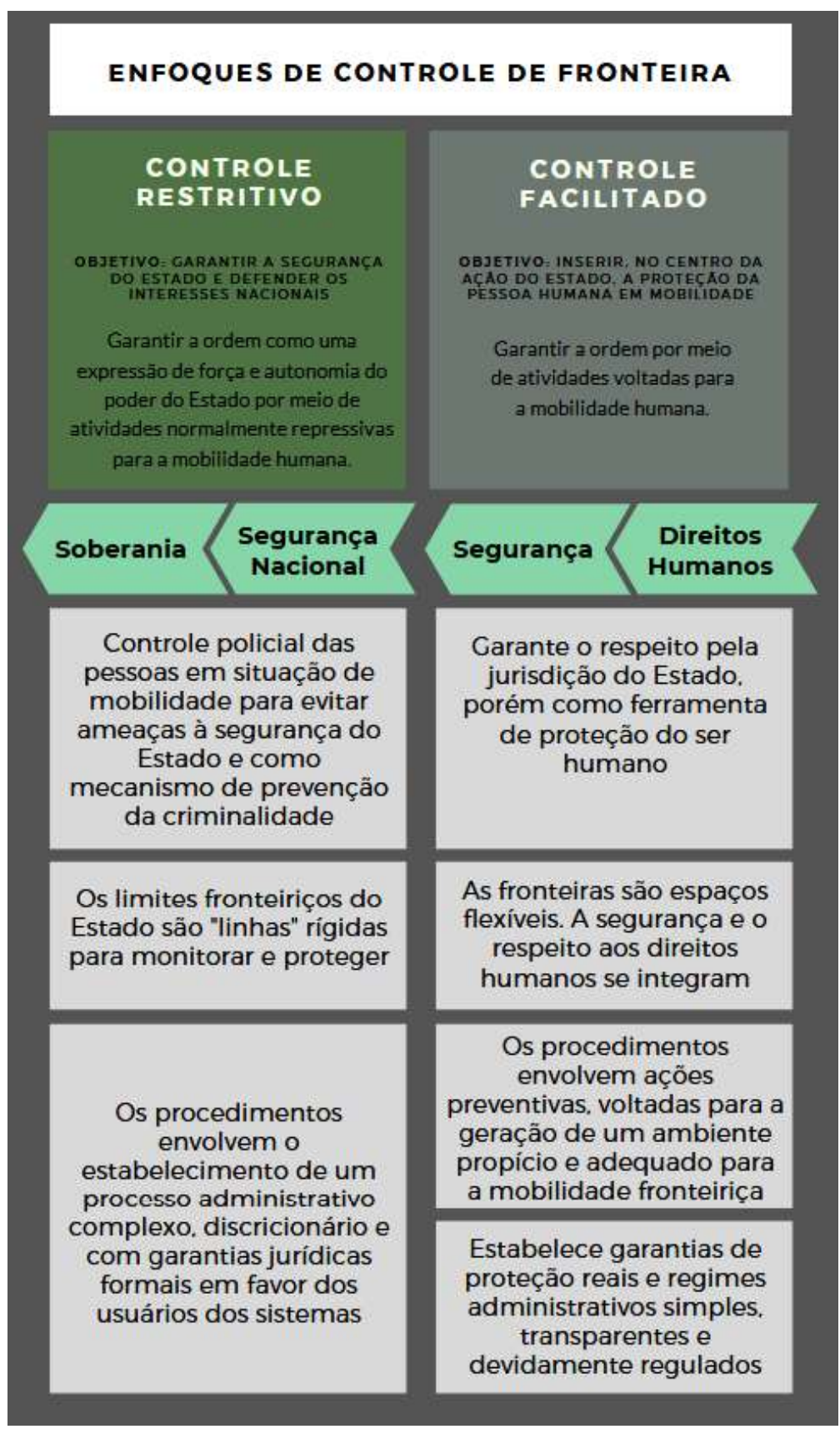

Fonte: Elaborado pelos autores

A Gestão Coordenada de Fronteiras implica em uma ordenação entre os órgãos públicos e o setor privado com o objetivo de me- 
lhorar o controle fiscal, a segurança das divisas, a facilitação do comércio e o trânsito de migrantes. Trata-se, portanto, do gerenciamento de funções e ações de todas as partes interessadas responsáveis pela regulamentação e controle de pessoas, veículos e mercadorias que atravessam fronteiras e que podem influenciar, de alguma forma, os interesses da sociedade, definidos em função do enfoque de controle adotado.

As diretrizes fundamentais ao adequado gerenciamento de fronteiras, qual seja, de forma integrada, segura e coordenada, são evidenciadas no $11^{\circ}$ objetivo do Pacto Mundial ${ }^{2}$, o qual se destaca por esclarecer as esferas que precisam ser robustecidas, além de servir como norteador para a atuação dos países, em que pese não ser cogente:

2 https://undocs.org/es/A/CONF.231/3 
Imagem 3 - Diretrizes fundamentais ao gerenciamento de fronteira

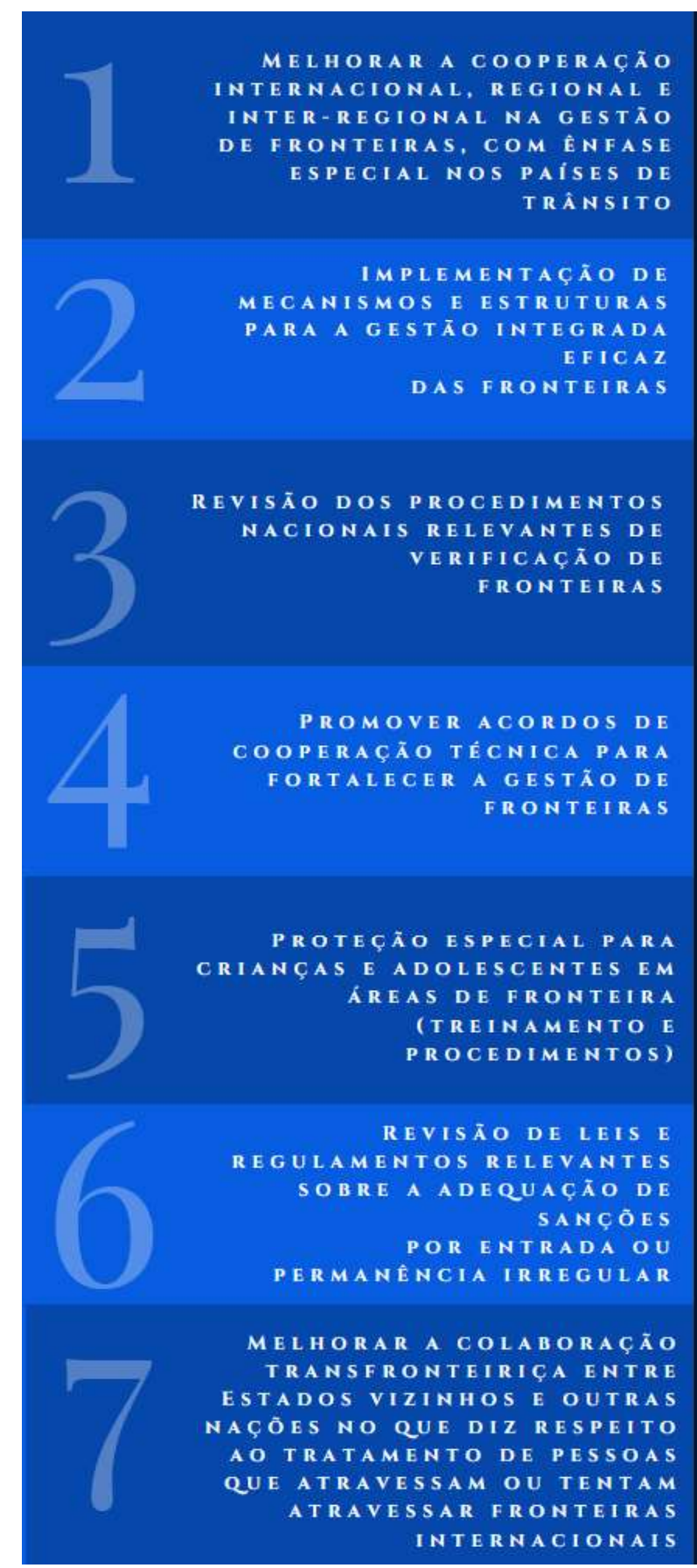

Fonte: Adaptado de Pacto Mundial

Ainda conforme as diretrizes do Pacto Mundial, a adequada gestão de fronteiras equilibra os anseios pátrios relacionados à segurança nacional, bem como ao deslocamento facilitado em seus limites territoriais. Para tanto, é essencial que as políticas e intervenções de gerenciamento de fronteiras sejam consolidadas em quatro áreas: 
Imagem 4 - Principais áreas de atuação no gerenciamento de fronteira

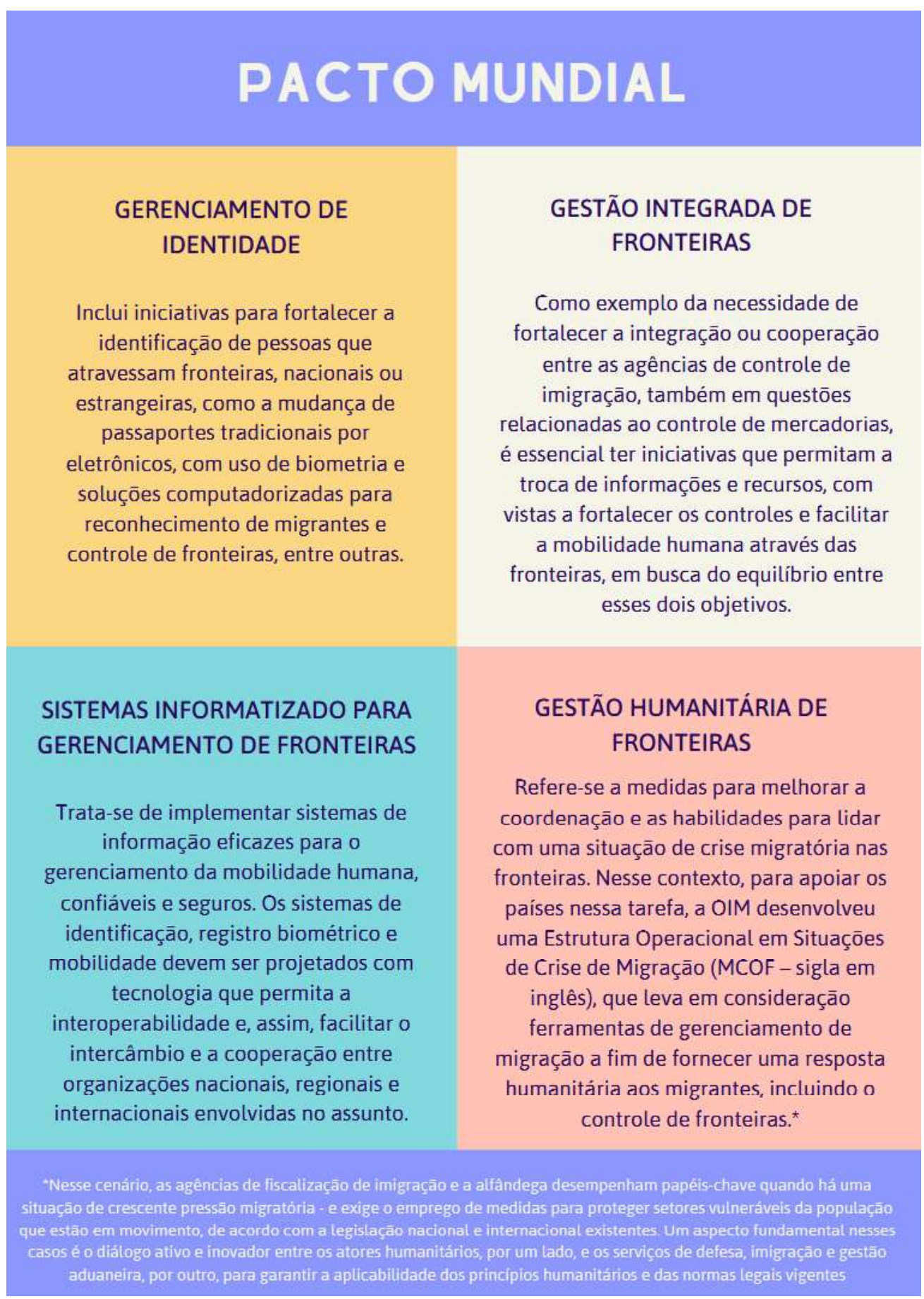

Fonte: Elaborado pelos autores

O fluxo de pessoas, mercadorias e veículos aliado à extensão e à diversidade local de nossas fronteiras demandam a necessidade governamental de gerenciar e coordenar as ações de todas as partes envolvidas nesse processo. Com efeito, a Gestão Coordenada de Fronteiras 
pode auxiliar a aperfeiçoar o trânsito de pessoas, o controle fiscal e a segurança de suas divisas a partir de uma estrutura de eficácia e eficiência, pelo que minimiza a duplicação de esforços e maximiza o uso eficiente dos recursos públicos por meio de procedimentos institucionais, nacionais e internacionais de forma integrada.

Por outro lado, a ausência de gerenciamento reduz substancialmente a eficácia dos controles e os benefícios das medidas de facilitação adotadas pelo país. Como reflexo, também é limitada a eficiência na aplicação dos recursos públicos. Ainda, a gestão integral e coordenada de fronteiras, envolve não somente o fluxo de pessoas, a questão da segurança e defesa nacional ou os controles aduaneiros, pelo que se deve considerar, também, a migração ordenada, segura e digna, a aplicação de medidas sanitárias eficazes e o fortalecimento de estratégias de saúde pública, entre outras.

É nesse contexto que a Gestão de Riscos (GR) pode auxiliar este processo, ao identificar, por intermédio de tratamento de informações, o equilíbrio entre o controle e a facilitação de acesso. Ou seja, até que ponto é possível facilitar a circulação de usuários de baixo risco e oferecer-lhes um tratamento diferenciado sem comprometer o controle fiscal, a segurança, a facilitação do comércio e o combate a crimes transfronteiriços.

\section{Gestão e Análise de Riscos}

O risco está presente no contexto dos negócios de todas as instituições, seja do setor público ou privado. No âmbito da Gestão Coordenada de Fronteiras, analisar o risco por meio de uma abordagem estruturada é fundamental, na medida em que se busca identificar e avaliar ameaças, e estabelecer estratégias e procedimentos para a sua devida prevenção e tratamento, seja sob o ponto de vista do Estado, seja sob o escopo do migrante.

O termo risco notabilizou-se na última metade do século passado (WILLIAMS, 1985), quando políticos, organizações civis, pesquisadores, especialistas, militares, editores e diversas instituições perceberam a necessidade de se enfrentar de maneira mais sistemática os 
problemas a ele relacionados (RENN, 2008). A partir de então, com a pesquisa e evolução dos métodos, algumas definições sobre riscos foram criadas, por meio de pesquisadores, normativos internos e normas internacionais (ANDRADE, 2017). No meio acadêmico e corporativo, há diversas definições aceitas para descrevê-lo, a depender da declaração do objetivo da análise ou do contexto definido:

- incerteza de resultado de ações e eventos (Orange Book ${ }^{3}$ );

- efeito da incerteza nos objetivos (ISO 31000:2018);

- risco é a possibilidade de que um determinado evento indesejável ocorra. (COSO II ERM 2004);

- possibilidade de ocorrência de um evento que venha a ter impacto no cumprimento dos objetivos (IN 01/20164).

Não obstante, os conceitos e as formas de se avaliar o risco variam em função do objetivo, da escolha de metodologias, da complexidade das medidas de risco e na atividade instrumental e social da sua perspectiva. Entretanto, é universal o entendimento de que risco é a incerteza dos resultados, ou seja, refere-se à hesitação quanto a futuros desdobramentos de um determinado evento (ANDRADE, 2017).

O risco é processado por intermédio de uma estrutura nomeada Análise de Riscos (AR), que, por sua vez, é uma ferramenta a ser desenvolvida em um processo mais amplo, conhecido como Gestão de Riscos. Esta é definida por um conjunto das atividades coordenadas para dirigir e controlar uma organização, ou um tema, no que se refere ao risco.

Portanto, a AR é o processo por meio do qual se entende a natureza do risco e a consequente determinação de seu nível, sendo base para a Gestão de Riscos (imagem 5), procedimento indicado para identificar o equilíbrio entre controle e facilitação em um gerenciamento eficiente de fronteiras.

3 Orange Book é uma publicação do governo do Reino Unido sobre procedimentos de análise de riscos, onde estabelece o conceito de gerenciamento de riscos e fornece uma introdução básica aos seus conceitos, desenvolvimento e implementação de processos de gerenciamento de riscos em organizações governamentais daquele país.

4 INSTRUÇÃO NORMATIVA CONJUNTA No 1 , de 10 de maio de 2016, que dispõe sobre controles internos, gestão de riscos e governança no âmbito do Poder Executivo federal. Disponível em <http://www.in.gov.br/materia/-/asset_publisher/Kujrw0TZC2Mb/content/id/21519355/ do1-2016-05-11-instrucao-normativa-conjunta-n-1-de-10-de-maio-de-2016-21519197> 
Imagem 5 - Gestão de riscos

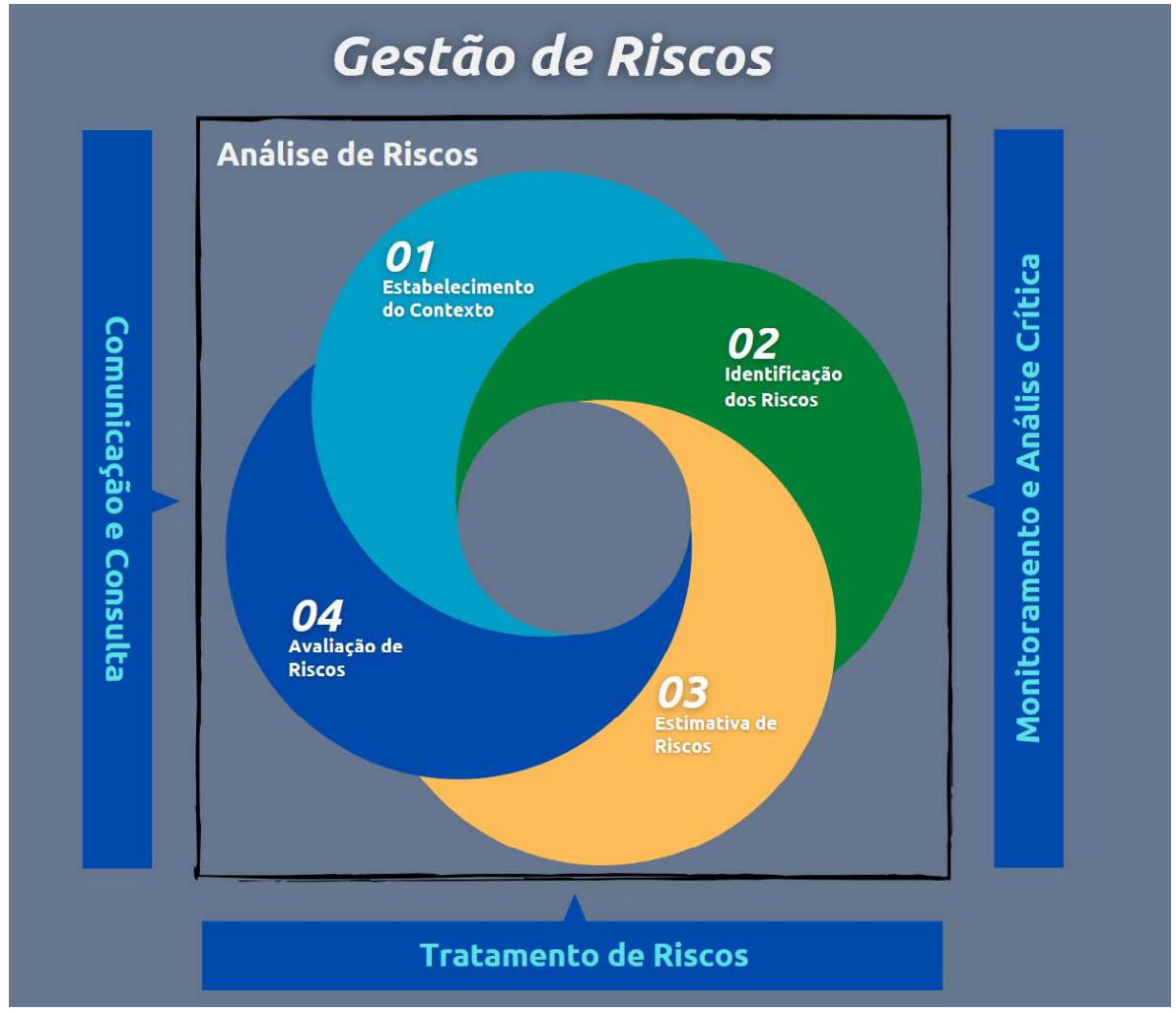

Fonte: Elaborado pelos autores

Embora existam diversas metodologias de análise de riscos, a modelagem específica deve ser concebida com base no objetivo que se deseja alcançar. Em outras palavras, para uma Gestão Coordenada de Fronteiras, a AR deve ser elaborada sob medida, pois é preciso considerar o contexto interno e externo de um dado país, suas peculiaridades, os respectivos normativos nacionais e internacionais, as dinâmicas de fluxos migratórios e os interesses nacionais associados.

Dessa forma, a imagem 5 refere-se à propositura de um framework genérico de Gestão de Riscos - que deverá ser instrumentalizado com ferramentas específicas - desenvolvido pelas seguintes fases: I) Estabelecimento do Contexto (políticas, cenários e prioridades do país); (II) Identificação de riscos, III) Estimativa de riscos; e IV) Avaliação de Riscos. Além das etapas, a estrutura sugere os seguintes processos: Monitoramento e Análise Crítica, Comunicação e Consulta e Tratamento de Riscos, em um círculo virtuoso contínuo que se retroalimenta e fortalece o modelo, transformando o processo de análise em GR. 
Nesse contexto, a Gestão de Riscos é um instrumento essencial para a Gestão Coordenada de Fronteiras, pois é capaz de tratar um complexo sistema de componentes correlacionados, como recursos, resultados ou objetivos desejados, proteção dos direitos humanos e a salvaguarda da sociedade: quanto melhor se entender a dinâmica fronteiriça em termos de riscos, melhor será a decisão governamental para a gestão integrada e eficaz das fronteiras.

A responsabilidade de se construir uma sociedade livre, justa e solidária, notadamente sob o ponto de vista da proteção dos direitos fundamentais dos migrantes, sem preconceitos de origem, raça, sexo, cor, idade e quaisquer outras formas de discriminação, traz consigo a necessidade de se compreender - e tratar - diversos temas correlatos como o tráfico de pessoas, contrabando de migrantes, grupos vulneráveis, questões sanitárias, crime organizado e terrorismo, especialmente no momento abrangido pela questão da pandemia, que tem alterados as relações humanas e potencializado vulnerabilidades (BAENINGER et. al., 2020).

Nesse cenário, manter a integridade dos mecanismos de migração e mobilidade exigem a capacidade estatal de encontrar um ponto de equilíbrio entre a proteção e a facilitação, pelo que é preciso detectar e coibir atividades ilegais nas fronteiras ao mesmo tempo em que é necessário garantir uma migração ordenada, segura e digna, sem criar barreiras desnecessárias para as pessoas que pretendem transpor a fronteira. É precisamente neste ponto que a análise de riscos pode auxiliar a Gestão Coordenada de Fronteiras.

$\mathrm{Na}$ medida em que controle e mobilidade influenciam-se mutuamente, gerando oportunidades e riscos como reflexo, os atos de governo relacionados à migração precisam ser disciplinados, e os procedimentos para o fluxo migratório estabelecidos, com base em análises, pesquisas e estudos. Para que isso ocorra, é indispensável que os atores envolvidos diretamente nessas tarefas estabeleçam procedimentos para coletar, analisar e usar informações, a fim de lidar não somente com o terrorismo, tráfico de pessoas, pandemias, contrabando de migrantes e outras atividades criminosas transfronteiriças, mas igualmente no sentido de oferecer proteção e assistência ao migrante. 
Esse ponto de equilíbrio pode ser obtido considerando o tipo de abordagem de controle que se pretende adotar em conjunto com a ferramenta de análise de riscos: instrumento que auxilia o planejamento das ações governamentais, tanto em nível estratégico como em nível tático. Com efeito, amplia-se a capacidade de se compreender e priorizar requisitos aparentemente concorrentes como a segurança e a mobilidade de pessoas.

Ademais, a ferramenta pode assessorar a tomada de decisão acerca das oportunidades trazidas pelos migrantes, e promover o crescimento econômico e o desenvolvimento social ao aproveitar as suas habilidades, dinamismo e inovação. Impulsionar o desenvolvimento social e a proteção de seus cidadãos permitem compreender a migração tanto sob o ponto de vista do migrante, quanto do Estado, como se supostamente fossem objetivos excludentes. Isto é, os governos enfrentam o dilema de adotar políticas que, à primeira vista, parecem contraditórias: por um lado, eles devem encontrar a melhor maneira de facilitar os movimentos legítimos de pessoas e, por outro, manter a segurança de suas fronteiras.

É presumível a impossibilidade de se realizar um controle exaustivo das fronteiras sem afetar negativamente a circulação de pessoas e o comércio e, consequentemente, o desenvolvimento do país. Sob outra perspectiva, a falta de procedimentos de proteção afeta os recursos públicos e a segurança dos cidadãos. Sem embargo, quanto mais refinada a $\mathrm{AR}$, melhor será o cumprimento das funções públicas ao se estabelecer procedimentos de triagem em função da detecção de riscos.

Por exemplo, amparar grupos vulneráveis suscetíveis a riscos e violência, ao prevenir ou mitigar os riscos a eles associados, evita a ocorrência ou agravamento de violações dos direitos humanos e, também, diminui a insegurança nas fronteiras. Isto é, situações de vulnerabilidade podem aumentar a probabilidade de vitimização de migrantes por redes criminosas transfronteiriças, como redes de tráfico de pessoas e contrabando de migrantes, pelo que se faz necessário um tratamento com dedicada atenção a esta categoria de migrantes.

Destarte, convém sistematizar o uso de dados e informações na produção do conhecimento com objetivo de se avaliar os eventos 
indesejados, na medida em que esse processo possibilita identificar e entender os possíveis reflexos das tendências migratórias, salvaguardar os direitos dos migrantes e prevenir os riscos associados à soberania nacional e criminalidade.

Nessa esteira, a aplicação do GR nos fluxos migratórios deve considerar dois aspectos: (I) os riscos do país de ingresso e (II) os riscos associados ao migrante, de acordo com suas vulnerabilidades e o motivo que o incentiva a migrar. Assim, convém que a análise considere todos os dados relacionados ao tema, como o fluxo migratório e comercial, a economia, os assuntos de interesse nacional, os direitos humanos, o crime, os riscos sanitários, o uso de recursos públicos, entre outros.

Em se tratando do ponto de vista do migrante, é importante identificar e avaliar os riscos associados especialmente à ocorrência de danos à integridade da pessoa, como ameaças à vida, saúde, segurança e situações sociais, culturais, econômicas e políticas que o colocam em condições de maior risco de violação de seus direitos humanos, ou que o impeçam de buscar melhores condições de vida e de trabalho.

Portanto, no contexto migratório, a GR pode auxiliar na definição de ações dentro da dinâmica de migração distintiva, ao identificar os riscos dos diferentes perfis de pessoas que cruzam a fronteira, como o migrante regular, que procura acessar ou transitar para um país específico, de acordo com a legislação de imigração, cumprindo os requisitos estabelecidos; o migrante que entra irregularmente; os grupos vulneráveis; entre outros. Daí a relevância das autoridades migratórias e dos órgãos de segurança nas fronteiras definirem processos de coleta sistematizada de informações, além de protocolos e conhecimentos necessários que alimentarão a Análise de Riscos a fim de identificar o perfil de migrantes vulneráveis e de pessoas que pretendem cometer qualquer tipo de irregularidade no país.

\section{Consideraçóes Finais}

O fluxo de pessoas, mercadorias e veículos aliados à extensão e à diversidade local de nossas fronteiras implicam a necessidade gover- 
namental em gerenciar e coordenar as ações de todas as partes envolvidas nesse processo. Dessa forma, a Gestão Coordenada de Fronteiras pode auxiliar a melhorar o trânsito de indivíduos, o controle fiscal e a segurança a partir de uma estrutura de eficácia e eficiência, pelo que minimiza a duplicação de esforços e maximiza o uso eficiente dos recursos públicos por meio de procedimentos institucionais, nacionais e internacionais de forma integrada.

Portanto, torna-se fundamental estabelecer uma forma de se priorizar quais operações e controles em áreas de fronteira devem se concentrar os esforços públicos. Nesse sentido, a análise de risco permite estabelecer métricas e critérios para maximizar a eficácia no uso de recursos, além de identificar um ponto de equilíbrio entre a proteção e a facilitação do acesso, podendo se tornar um vetor importante para o desenvolvimento do país, especialmente no momento presente de retomada da dinâmica migratória ainda em meio aos riscos sanitários existentes determinados pela Covid-19.

Finalmente, para uma gestão eficaz de fronteiras, é preciso instrumentalizá-la com um procedimento de gestão de riscos integral, que considera diversos fatores de influência, tanto sob o ponto de vista do Estado, quanto do migrante, que, em última análise, se convergem para um mesmo objetivo: construir uma sociedade livre, justa e solidária, na proteção dos direitos fundamentais e no interesse legítimo dos países em salvaguardar a segurança nacional, seja em questões ambientais e sanitárias, seja no combate a atividades criminosas transnacionais. Trata-se da convergência entre os direitos humanos e a segurança nacional, compreendida por meio da análise de riscos e implementada através da Gestão Coordenada de Fronteiras.

BIOGRAFIA DO(A)S AUTORE(A)S:

Felipe Scarpelli de Andrade

Mestre em Gestão de Riscos com ênfase na Segurança Pública pela Universidade Federal de Pernambuco. ANALISTA DE INTELIGÊNCIA ESTRATÉGICA FORMADO PELA Escola Superior de Guerra (ESG). Especialista em Inteligência de Segurança Pública pela Universidade Sul de Santa Catarina; MBA em Gestão de Riscos na metodologia Brasiliano. Agente de Polícia Federal. Atualmente chefe do Serviço de Análise Estratégica, da Diretoria de Inteligência Policial. Professor da 


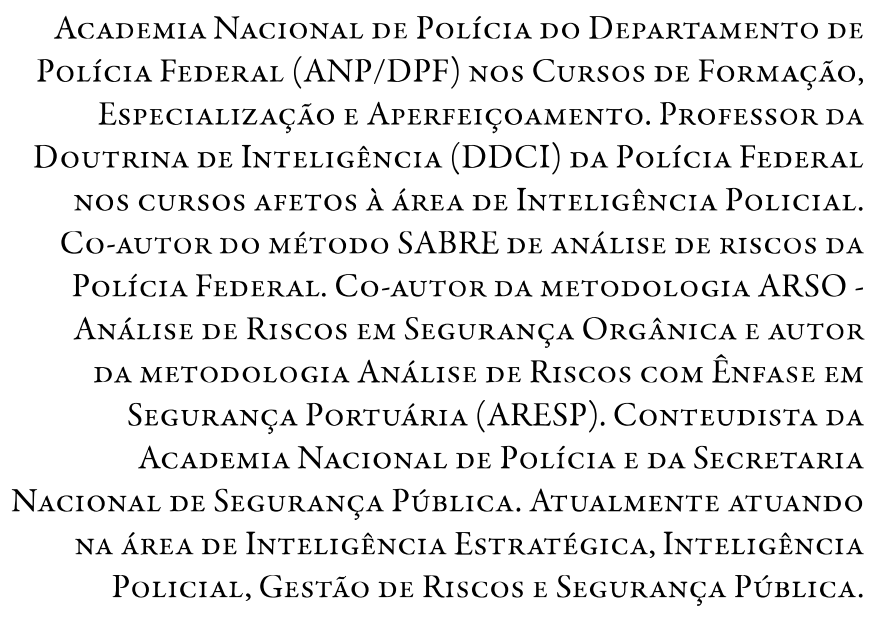

Priscila Aparecida de Macêdo e Silva

Escrivã de Polícia Federal lotada no Serviço de Análise Estratégica dA Diretoria de Inteligência Policial.

\section{REFERÊNCIAS}

ANDRADE, F. S. Análise de Riscos e a Atividade de Inteligência. Revista Brasileira de Ciências Policiais, v.8(2), p. 91116, 2017. DOI: 10.31412\%2Frbcp.v8i2.462.

AVEN, T. Risk assessment and risk management: Review of recent advances on their foundation. European Journal of Operational Research. v. 253, p. 1-13, 2016. DOI: 10.1016/j. ejor.2015.12.023

AVEN, TERJE et al. SRA Glossary. Committee on Foundations of Risk Analysis. Society of Risk Analysis, London. 2015.

AVEN, T.; ZIO, E. Foundational issues in risk analysis. Risk Analysis, v. 34 (7), p. 1164-1172, 2014.

Banco Interamericano de Desenvolvimento (BID): curso de Gestión Coordinada de las Migraciones en Fronteras, Módulo 1, Ámbitos de Regulación.

BAENINGER, Rosana; CANALES, Alejandro (Coords.). Migrações Fronteiriças. Campinas: Núcleo de Estudos de 
População "Elza Berquó" -Nepo/Unicamp, 2018. Disponível em: $<$ https://www.nepo.unicamp.br/publicacoes/livros/mig fronteiricas.pdf $>$. Acesso em 01 jun. 2021.

BAENINGER, Rosana; VEDOVATO, Luís Renato (Coords.). Migraçôes Internacionais e a pandemia de Covid-19. Campinas: Núcleo de Estudos de População "Elza Berquó" -Nepo/Unicamp, 2020. Disponível em: <https://www.nepo.unicamp.br/publicacoes/ livros/miginternacional/miginternacional.pdf $>$. Acesso em 04 jun. 2021.

BRASIL. Constituição da República Federativa do Brasil de 1988: texto constitucional promulgado em 5 de outubro de 1988, com as alterações determinadas pelas Emendas Constitucionais de Revisão no 1 a 6/94, pelas Emendas Constitucionais no 1/92 a 99/2017. Brasília/DF: Senado Federal, Coordenação de Edições Técnicas, 2017.

BRASIL; OIM. Guia de Interiorização 2021 - Deslocamento voluntário de refugiados e migrantes. Diretrizes e procedimentos. Brasília: OIM, 2021. Disponível em: <https://brazil.iom.int/sites/ brazil/files/Publications/Guiadedeslocamentosassistidosweb_0.p>. Acesso em 04 jun. 2021.

COMMITTEE OF SPONSORING ORGANIZATIONS OF THE TREADWAY COMISSION - COSO. Enterprise Risk Management - Integrated Framework, 2017.

COMMITTEE OF SPONSORING ORGANIZATIONS OF THE TREADWAY COMISSION - COSO. Enterprise Risk Management - Integrated Framework (Executive Summary), 2013. COMMITTEE OF SPONSORING ORGANIZATIONS OF THE TREADWAY COMMISSION - COSO. Gerenciamento de Riscos Corporativos - Estrutura Integrada, 1992.

COMMITTEE OF SPONSORING ORGANIZATIONS OF THE TREADWAY COMMISSION - COSO. The 2013 COSO framework \& SOX compliance: one approach to an effective transition, 2013.

CORREIA, Theresa Rachel Couto. Globalização, migração internacional e Direitos Humanos. In: Conpedi. (Org.). XVIII 
Congresso Nacional do Conpedi. 1ed. Florianópolis: Fubdação Boiteux, 2009, v. , p. 8881-8892. Disponível em: <http://www. publicadireito.com.br/conpedi/manaus/arquivos/Anais/sao_ paulo/2540.pdf>. Acesso em 31 de mai. 2021.

DUVAL, Fernandes; BAENINGER, Rosana (Coords.). Impactos da Pandemia de COVID-19 nas Migraçóes Internacionais no Brasil. Resultados de Pesquisa. Campinas: Núcleo de Estudos de População "Elza Berquó" - Nepo/Unicamp, 2020. Disponível em: <https:// www.nepo.unicamp.br/publicacoes/livros/impactos_pandemia/ COVID\%20NAS\%20MIGRA\%C3\%87\%C3\%95ES\%20 INTERNACIONAIS.pdf>. Acesso em 03 jun. 2021.

IBGE. Brasil: 500 anos de povoamento. Centro de Documentação e Disseminação de Informações. Rio de Janeiro: IBGE, 2007. Disponível em: <https://biblioteca.ibge.gov.br/visualizacao/livros/liv6687. pdf $>$. Acesso em 31 mai. 2021.

INTERNATIONAL ORGANIZATION FOR STANDARTIZATION, Risk management - Risk assessment techniques. ISO/IEC 31010:2009. Geneva. 2009.

INTERNATIONAL ORGANIZATION FOR STANDARTIZATION. Risk management - Principles and guidelines. ISO 31000:2018, Geneva. 2018.

MARTINE, George. A globalização inacabada: migrações internacionais e pobreza no século 21. São Paulo Perspec., São Paulo, v. 19, n. 3, p. 3-22, Sept. 2005. Disponível em: <https://www.scielo. $\mathrm{br} / \mathrm{j} / \mathrm{spp} / \mathrm{a} / \mathrm{ddmq} 64 \mathrm{Q} 3 \mathrm{LR} 7 \mathrm{dwYJYcNR} 4 \mathrm{pQf} /$ ?lang=pt $>$. Acesso em 31 mai. 2021.

OBMIGRA. Acompanhamento de fluxo e empregabilidade dos imigrantes no Brasil: Relatório Mensal do OBMigra. Ano 0, Números 1 - 12. Brasília, DF: OBMigra, 2019. Disponível em: <https:// portaldeimigracao.mj.gov.br/pt/dados/relatorios-mensais $>$. Acesso em 01 jun. 2021.

OBMIGRA. Acompanhamento de fluxo e empregabilidade dos imigrantes no Brasil: Relatório Mensal do OBMigra. Ano 1, Números 1-12. Brasília, DF: OBMigra, 2020. Disponível em: <https:// portaldeimigracao.mj.gov.br/pt/dados/relatorios-mensais $>$. Acesso em 02 jun. 2021. 
OIM. COVID-19 and the State of Global Mobility in 2020. Genebra: Organização Internacional para as Migrações, 2021. Disponível em: $<$ https://brazil.iom.int/sites/brazil/files/Publications/covid-19-andthe-state-of-global.pdf $>$. Acesso em 02 de jun. 2021.

OIM. Direito Internacional da Migração: Glossário sobre Migrações. Genebra: Organização Internacional para as Migrações, 2019. Disponível em: <https://publications.iom.int/system/files/pdf/ iml_34_glossary.pdf $>$. Acesso em 04 jun. 2021.

OIM. Migrations Trends in South America (march 2020). South American Migration Report n. ${ }^{\circ}$ 3, 2020. Disponível em: <https:// robuenosaires.iom.int/sites/robuenosaires/files/Informes/ Migration_Trends_final.pdf $>$. Acesso em 01 jun. 2021.

OIM. World migration report 2018. Genebra: OIM, 2018.

RENN, O. Concepts of risk: a classification. Social theories of risk. Westport, Conn, p. 53-79, 1992. DOI: 10.18419/opus-7248.

RENN, O. Risk Governance. Coping with Uncertainty in a Complex World. Ed. Routledge, London, 2008.

RENN, O. Three decades of risk research: accomplishments and new challenges. Journal of Risk Research, v. 1(1), p. 49-71, 1998. DOI:10.1080/136698798377321

TORELLY, Marcelo; KHOURY, Aline; VEDOVATO, Luís Renato; GONÇALVES, Veronica Korber. Visões do Contexto Migratório no Brasil. Volume I. Brasília: Organização Internacional para as Migrações, Agência das Nações Unidas Para as Migrações, 2017. Disponível em: <https://portaldeimigracao.mj.gov.br/ images/publicacoes/visoes_do_contexto_migratorio_no_brasil_ VOLUME1.pdf $>$. Acesso em 04 de jun. 2021.

UNITED KINGDOM. The Orange Book Management of Risk Principles and Concepts. HM Treasury, London, 2013.

WILLIAMS, R. Keywords: a vocabulary of culture and society. Ed. Oxford University Press, New York, 1985. 


\section{INFORMAÇÕES ADICIONAIS E DECLARAÇÕES DOS AUTORES}

\section{(integridade cientifica)}

Declaração de conflito de interesse: $\mathrm{O}(\mathrm{s})$ autor(es) confirma(m) não haver conflitos de interesse na condução desta pesquisa e na redação deste artigo.

Declaração de autoria: Todos e apenas os pesquisadores que atendem os requisitos de autoria deste artigo são listados como autores; todos os coautores são integralmente responsáveis por este trabalho em sua totalidade.

Declaração de originalidade: $\mathrm{O}(\mathrm{s})$ autor(es) assegura(m) que o texto aqui publicado não foi previamente divulgado em qualquer outro local e que a futura republicação apenas será feita com expressa referência desta publicação original; também atesta(m) que não há plágio de material de terceiros ou autoplágio.

\section{Como Citar (Abnt BrasiL)}

ANDRADE, Felipe Scarpelli de; SILVA, Priscila Aparecida de Macêdo e. Análise de riscos na gestão coordenada de fronteiras: a convergência entre os direitos humanos e a segurança nacional na migração internacional. Revista Brasileira de Ciências Policiais, Brasília, vol. 13, n. 7, p. 387-408, jan./abr. 2022.

https://doi.org.br/10.31412/rbcp.v13i7.862

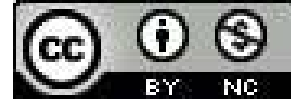

Esta obra está licenciada com uma Licença Creative Commons Atribuição-NãoComercial 4.0 Internacional. 


\section{SOBRE A REVISTA}

Formato: $16 \times 24 \mathrm{~cm}$

Mancha: $37 \mathrm{p} 9,543 \times 54 \mathrm{p} 3,969$

Tipologia:

Várias

Papel:

Offset $75 \mathrm{~g} / \mathrm{m}^{2}$ (miolo)

Supremo $250 \mathrm{~g} / \mathrm{m}^{2}$ (capa)

Vol. 13 n. 7 , jan./abri. 2022.

Equipe de Realização

Projeto Editorial

Coordenação Escola Superior de Polícia

Edição de Texto

Stenio Santos Sousa

Editoração

QueIrian Sá

Gleydiston Rocha

Normalização

Sônia Luiza de Oliveira

Virgílio Vieira de Melo Junior

Revisão e Tradução (Português-Espanhol)

Michelle Staphane Marques da Silva

Universidade Federal de Goiás (UFG) - Revisão dos Artigos

Impressão e Encadernação

EQuipe Nugraf/DAD/ANP

ACADEMIA NACIONAL DE POLÍCIA

Coordenação Escola Superior de Polícia 